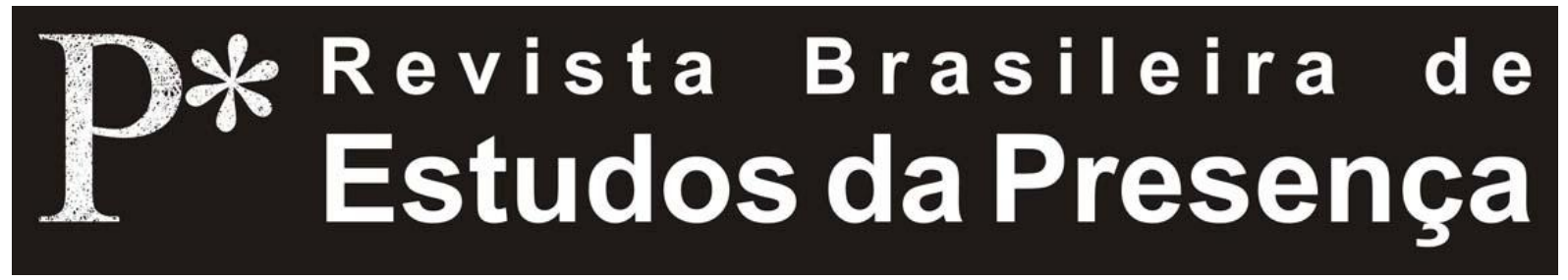

\title{
O Entrelaçamento dos Estudos Modernos da Performance e as Correntes Atuais em Antropologia
}

\author{
Marvin Carlson \\ The City University of New York, EUA
}

\begin{abstract}
RESUMO - O Entrelaçamento dos Estudos Modernos da Performance e as Correntes Atuais em Antropologia - Este texto propõe uma discussão da relação entre a Performance, o Teatro e a Antropologia. Apresentam-se as origens das relações entre performance e antropologia, elencando as principais ideias dos pioneiros norte-americanos e franceses. Comparam-se os relacionamentos entre artistas e antropólogos como Richard Schechner e Victor Turner, Eugenio Barba e Kirsten Hastrup. Por fim, problematiza-se os movimentos e as diferentes compreensões de performance e a forma produtiva como a relação entre performance e antropologia foi sendo construída nos últimos anos.

Palavras-chave: Performance. Teatro. Estudos da Performance. Antropologia.
\end{abstract}

\begin{abstract}
The Inter-twining of Modern Performance Studies and Current Trends in Anthropology - This paper discusses the relation between Performance, Theatre and Anthropology. We present the origins of the relations between performance and anthropology, listing the main ideas from NorthAmerican and French pioneers. We compare the connections between artists and anthropologists like Richard Schechner and Victor Turner, Eugenio Barba and Kirsten Hastrup. Finally, we discuss the movements and the different apprehensions of performance and the productive way in which the relation between performance and anthropology has been built in recent years.
\end{abstract}

Marvin Carlson, O Entrelaçamento dos Estudos Modernos da Performance e as Correntes Atuais em Antropologia

R.bras.est.pres., Porto Alegre, v.1, n.1, p. 164-188, jan./jun., 2011.

Disponível em http://www.seer.ufrgs.br/presenca 
Keywords: Performance. Theatre. Performance Studies. Anthropology.

RÉSUMÉ - L'Entrecroisement des Études Modernes de la Performance et des Courants Actuels en Anthropologie - Ce texte propose une réflexion sur le rapport existant entre la performance, le théâtre et l'anthropologie. Présentant les origines des relations entre performance et anthropologie, il répertorie les principales idées des pionniers nord-américains et français. Il propose ensuite une lecture comparative des relations nouées entre artistes et anthropologues comme Richard Schechner et Victor Turner, Eugenio Barba et Kirsten Hastrup. Enfin, il s'agit de s'interroger sur la question des mouvements et des différentes conceptions de la performance, ainsi que sur la manière productive selon laquelle la relation entre performance et anthropologie a été construite ces dernières années.

Mots-clés: Performance. Théâtre. Études de la Performance. Anthropologie.

O desenvolvimento do campo dos estudos da performance, especialmente como tem se dado nos Estados Unidos, deve sua origem à convergência de interesses de pesquisa teatrais e das ciências sociais, os quais tomam lugar em meados do século XX. Embora certos teóricos das ciências sociais tenham antecipado elementos dessa convergência, tal como com Nicolai Evreinov (1970), na Rússia do começo do século XX, a maior exploração se deu na França em meados de 1950, inspirada em parte pelos teóricos marxistas - os quais já demonstravam natural interesse nas operações sociais das artes.

O primeiro grande encontro de teóricos interessados na sociologia do teatro foi realizado em Royaumont, em 1955. O foco dessa conferência e do primeiro livro mais importante neste campo foi o deveras influente Sociologia do Teatro, de Jean Duvignaud (1963), lançado em 1962, o qual se tratava antes de uma análise sociológica do teatro do que sobre o uso de conhecimentos teatrais na sociologia; essa possibilidade foi sugerida de maneira específica na súmula principal da conferência de Royamont, no artigo do sociológo George

Marvin Carlson, O Entrelaçamento dos Estudos Modernos da Performance e as Correntes Atuais em Antropologia

R.bras.est.pres., Porto Alegre, v.1, n.1, p. 164-188, jan./jun., 2011.

Disponível em http://www.seer.ufrgs.br/presenca 
Gurvitch, também chamado de Sociologia do Teatro (1956), lançado em 1956.

Nesse ensaio, Gurvitch não apenas comentou sobre a dimensão social do teatro, mas, muito mais presciente, destacou a importância dos elementos teatrais ou de performance em toda sorte de cerimônia social, mesmo em "[...] uma recepção simples ou uma reunião de amigos" (Gurvitch, 1956, p. 197).

De forma concomitante a essa nova orientação na França, um número de cientistas sociais nos Estados Unidos começou a desenvolver análises que tinham muito em comum com as sugestões de Gurvitch, concebendo modelos teatrais e dramáticos como ferramentas para a compreensão de relações sociais não-teatrais. Os mais influentes dentre esses foram o sociólogo Erving Goffman e o antropólogo Victor Turner. O livro mais conhecido de Goffman data de 1956 e se intitula a Presentificação do eu na vida cotidiana ${ }^{1}$, obra que tornou corrente o conceito de performance social como uma espécie de dramatização. O capítulo introdutório dessa obra recebeu o nome de Performance e nele Goffman definiu a performance social em termos surpreendemente teatrais, como sendo "[...] toda atividade de um indivíduo que ocorra durante um período marcado por sua presença contínua mediante um conjunto de observadores e a qual possui alguma influência sobre os mesmos" (Goffman, 1956, p. 22).

No ano seguinte ao lançamento de The Presentation of Self in Everyday Life (Presentificação do eu na vida cotidiana), em 1957, Victor Turner introduziu em seu estudo Schism and Continuity, o conceito por ele chamado de drama social, tomando-o como ferramenta para antropólogos sociais. Nele, Turner desenvolveu um modelo da forma cultural específica de teatro para aplicar a um corpo muito maior de manifestações culturais. Em trabalhos posteriores, como o de 1974 Dramas, Fields and Metaphors e From Ritual to Theatre, de 1982, Turner ampliou a estratégia analítica do drama social do nível da aldeia, presente na obra Schism and Continuity, a uma ampla variedade de situações históricas. Em cada um desses dramas sociais, Turner traçou um padrão

Marvin Carlson, O Entrelaçamento dos Estudos Modernos da Performance e as Correntes Atuais em Antropologia

R.bras.est.pres., Porto Alegre, v.1, n.1, p. 164-188, jan./jun., 2011.

Disponível em http://www.seer.ufrgs.br/presenca 
recorrente, o qual ele comparou com a forma da ação dramática: primeiro, uma violação de uma norma estabelecida e socialmente aceita; disso decorre, então, uma crise crescente, na medida em que se formam facções; tal crise é seguida por um processo de negociação o qual opera como mecanismo de resolução da mesma, e, finalmente, uma reintegração, a qual envolve tanto o ajustamento a uma situação cultural original quanto o reconhecimento da permanência do cisma.

Embora o trabalho de Goffman e Turner tenha sido sobremaneira influente dentro de seus próprios campos e, em particular, o de Goffman, para um público mais geral - o trânsito entre a teoria do teatro e a ciência social permaneceu, na maior parte do tempo, num sentido único durante os anos de 1960, todavia, um importante passo exploratório em direção a uma dinâmica mais recíproca foi sugerido por Richard Schechner em um editorial para um número de 1966 da revista The Drama Review, intitulado Approaches to Theory/Criticism. Ao começar seu ensaio com o trabalho de antropólogos de Cambridge (Gilbert Murray, F.M. Cornford e Jane Ellen Harrison), Schechner sugeriu que essa abordagem, como a Nova Crítica e o estudo histórico e biográfico, tinha se revelado inadequado para a análise do teatro, a qual deveria ser baseada não em preocupações textuais, mas na ação. Ele sugeriu como uma possível ferramenta para tal a "[...] análise de jogo, matemática e transacional, a construção de modelos e comparações entre o teatro e outras situações de performance" (Schechner, 1966, p. 26), em referência a obra de Goffman, assim como da de LéviStrauss, do pioneiro da análise transacional Eric Berne e os teóricos do jogo Johan Huizinga e Roger Caillois.

Apesar da proeminência da revista The Drama Review, que naquele momento era largamente reconhecida como a principal voz da teoria contemporânea e da prática no teatro americano, esse artigo não teve de imediato muito impacto. Entretanto, em 1973, ou seja, seis anos mais tarde, uma exploração mais elaborada e focada dessas ideias pôde ser vista como o grande impulso para o desenvolvimento do que veio a

Marvin Carlson, O Entrelaçamento dos Estudos Modernos da Performance e as Correntes Atuais em Antropologia

R.bras.est.pres., Porto Alegre, v.1, n.1, p. 164-188, jan./jun., 2011.

Disponível em http://www.seer.ufrgs.br/presenca 
ser conhecido como os Estudos da Performance, os quais têm grande parte de sua inspiração original na reunião de métodos de análise e modelos provenientes do teatro e das ciências sociais, em particular da sociologia e da antropologia.

Schechner já não era mais o editor da revista The Drama Review; ele havia renunciado a essa posição em 1969, voltando a servir como editor convidado, no outono de 1973, para uma edição especial dedicada ao tema Teatro e as Ciências Sociais. Em sua introdução a esse número, Schechner pontuava o "[...] início de um esforço para estabelecer de uma forma sistemática um continuum entre as ciências sociais e a performance" (1973, p. 9). O que Schechner propunha era um novo campo de estudo o qual ele chamou de Teoria da Performance. Ele propôs sete áreas "[...] em que a teoria da performance e as ciências sociais [coincidiriam]", áreas que já haviam sido como que sugeridas por Gurvitch, mas que se afastavam do teatro em direção ao comportamento humano em geral. Essas sete áreas que Schechner descreveu foram: 1) a performance na vida cotidiana, incluindo reuniões de qualquer espécie; 2) a estrutura do esporte, do ritual, do jogo e dos comportamentos público-políticos; 3) a análise de vários outros modos de comunicação além da palavra escrita; 4) as conexões entre comportamento humano e animal com ênfase no jogo e nos comportamentos ritualizados; 5) os aspectos de psicoterapia que enfatizam a interação pessoa a pessoa, acting out e consciência corporal; 6) a etnografia e a pré-história - tanto de culturas exóticas quanto familiares; 7) a constituição de teorias unificadas de performance, as quais são, de fato, teorias do comportamento (Schechner, 1973, p. 9).

Ainda que Schechner tenha evocado a obra de Lévi-Strauss em 1966 e novamente em 1973, a obra de Victor Turner era, aparentemente, ainda desconhecida para ele, muito embora fosse mais diretamente relevante para o seu projeto. De acordo com Turner, amigos em comum chamaram sua atenção ao fato de que Schechner estava estudando, do ponto de vista do teatro, certos aspectos da performance cultural - a qual Turner estava considerando do ponto de vista antropológico. Os dois

Marvin Carlson, O Entrelaçamento dos Estudos Modernos da Performance e as Correntes Atuais em Antropologia

R.bras.est.pres., Porto Alegre, v.1, n.1, p. 164-188, jan./jun., 2011.

Disponível em http://www.seer.ufrgs.br/presenca 
fizeram contato e, de fato, encontraram convergências significativas em seus trabalhos. Em 1976, quando Schechner publicou sua primeira coleção de ensaios sobre Teoria da Performance, Turner foi um dos seis teóricos convidados; além de Schechner, juntavam-se a eles Erving Goffman, os etnólogos Konrad Lorenz e Jane van Lawick-Goodall e o cientista da comunicaçãoc Ray Birdwhistell. Em 1977, Turner convidou Schechner para participar de uma conferência patrocinada pela Fundação Wenner-Gren para a Pesquisa Antropológica, dedicada ao tema Quadros culturais e reflexões: ritual, drama $e$ espetáculo. Schechner chamou essa conferência de um momento decisivo em sua vida acadêmica. Para essa encontro, Schechner escreveu um de seus artigos mais influentes, A restauração do comportamento. $\mathrm{O}$ comportamento restaurado de Schechner tornou-se um conceito central na Teoria da Performance subsequente e tem sido utilizado na análise de uma gama muito ampla de atividades culturais. De acordo com Schechner, tal comportamento envolve uma sequência de eventos que buscam a repetição, todavia corrompidos pelo mito ou pela memória, de alguma sequência anterior ou original, que é vista como tendo especial relevância para a cultura em que ela ocorre. Os performers de comportamento restaurado devem estar cientes da distância entre esse comportamento e sua realidade cotidiana, a qual é tomada como operando em um plano diferente de existência. Como exemplos de comportamento restaurado, Schechner reúne uma grande variedade de fenômenos até então estudados por teóricos em uma ampla variedade de campos das ciências humanas e sociais: o xamanismo, o exorcismo, o transe, o ritual, dança e teatro, ritos de iniciação, os dramas sociais descritos por Turner, a psicanálise, o psicodrama e a análise transacional (Schechner, 1985, p. 35).

Uma íntima relação de amizade se desenvolveu entre Schechner e Turner a partir da conferência de 1977, assim como um criativo intercâmbio de ideias que influenciaram poderosamente o trabalho de ambos os teóricos e, por intermédio deles, seus respectivos campos. Eles organizaram em conjunto uma série de conferências

Marvin Carlson, O Entrelaçamento dos Estudos Modernos da Performance e as Correntes Atuais em Antropologia

R.bras.est.pres., Porto Alegre, v.1, n.1, p. 164-188, jan./jun., 2011.

Disponível em http://www.seer.ufrgs.br/presenca 
sobre performance e, no verão de 1979 , ministraram uma oficina de performance junto a um grupo de estudiosos, estudantes de pós-graduação, realizada na Performing Garage, em Nova Iorque, que, naquele momento, estava sob a direção de Schechner. Essa oficina foi discutida tanto na coletânea de ensaios de Schechner de 1990, intitulada By Means of Performance, como no último livro de Turner From Ritual to Theatre, de 1982.

De acordo com Turner, essa oficina foi concebida como um laboratório intensivo para a exploração de uma "[...] interface entre o ritual e o teatro [...] entre drama social e drama estético", como também outros pontos de convergência "[...] entre as ciências sociais e as artes cênicas". A experiência da oficina, relatou Turner, "[...] me convenceu de que a cooperação entre pessoas antropológicas e pessoas teatrais não era apenas possível como também poderia se tornar uma grande ferramenta de ensino para ambos os conjuntos de parceiros" (Turner, 1982, p. 90-91). Para Schechner, a oficina lançou as bases para o que Turner e sua esposa Edith chamaram de etnografia performativa (performing ethnography). $\mathrm{O}$ mesmo se aplica à fundação do campo dos Estudos da Performance, o qual Schechner estava consolidando. From Ritual to Theatre, de Turner, foi o livro que melhor resultou desse trabalho, sendo, apropriadamente, o primeiro volume de uma série de publicações editada por Schechner e dedicada aos Estudos da Performance.

Como matéria-prima dessa oficina, Turner utilizou, não surpreendentemente, material de sua pesquisa realizada na África entre a tribo $N d e m b u$, material que ele já havia apresentado no que ele chamava de dramas sociais. Ele, sua esposa Edith e estudantes participantes, sendo alguns do teatro e outros da antropologia, trabalharam a partir disso para tornar esses scripts em performances encarnadas, um processo que Turner sugeria poder servir como um modelo para futuras colaborações "[...] entre antropólogos e profissionais do teatro e da dança" (1982, p. 74). Turner sentiu, e isso é o mais importante, que tais colaborações poderiam oferecer um meio para superar o dualismo cartesiano, o qual havia tradicionalmente dominado a pesquisa e a análise

Marvin Carlson, O Entrelaçamento dos Estudos Modernos da Performance e as Correntes Atuais em Antropologia

R.bras.est.pres., Porto Alegre, v.1, n.1, p. 164-188, jan.jun., 2011.

Disponível em http://www.seer.ufrgs.br/presenca 
antropológica. Tal dualismo, que separa o sujeito do objeto, o nós do eles, fazendo do homem ocidental um voyeur, um observador supostamente objetivo de um Outro explorado e alienígena. Sendo assim, argumentava Turner, "[...] os laços profundos entre corpo e mentalidade, o pensamento inconsciente e o pensamento consciente, entre as espécies e o eu têm sido tratadas de forma desrespeitosa, como se fossem irrelevantes para os propósitos da análise" (Turner, 1982, p. 74). A reflexividade da performance, contudo, dissolve esses laços, concebendo sujeito e objeto com o fim de criar o modo caracteristicamente pós-moderno de intersubjetividade. Por intermédio de tal reflexividade, representantes de uma modalidade mais genérica de existência humana, a experiência histórica ocidental, procuram não simplesmente observar, mas alcançar uma compreensão incorporada de outros modos até então trancados, nas palavras de Turner, "[...] por chauvinismo cognitivo ou esnobismo cultural" (Turner, 1982, p. 74).

A convergência entre o teatro e a antropologia na obra de Schechner e Turner, no final dos anos de 1970, veio em um momento de grande mudança na autocompreensão de ambos os campos de estudo; essa mudança foi, ademais, em ambos os campos, influenciada pelo interesse desses dois estudiosos de ponta na disciplina um do outro. Como já prenunciava Schechner, em seus artigos de 1966 e 1973, os Estudos da Performance se desenvolveram durante a década seguinte para então se tornar uma das principais áreas de pesquisa para estudiosos do teatro, mudando o campo de seu foco tradicional, a encenação do texto teatral, para questões de outra vasta área de atividades de performance no âmbito das culturas. A Universidade de Nova Iorque, na qual Schechner lecionara, estabeleceu, em 1980, o primeiro departamento de Estudos da Performance, sendo recebida uma folclorista, Barbara Kirshenblatt-Gumblatt, para servir como chefe desse novo departamento. Peggy Phelan, que se vinculou ao programa em 1985, escreveu mais tarde que a colaboração entre Turner e Schechner havia se constituído como o alicerce de um novo campo de estudo.

Marvin Carlson, O Entrelaçamento dos Estudos Modernos da Performance e as Correntes Atuais em Antropologia

R.bras.est.pres., Porto Alegre, v.1, n.1, p. 164-188, jan./jun., 2011.

Disponível em http://www.seer.ufrgs.br/presenca 
Ao trazerem teatro e antropologia juntos, ambos os homens viram questões de grande profundidade que fizeram irromper essas perspectivas sobre a experiência cultural. Se a diversidade da cultura humana mostrou continuamente uma persistente teatralidade, poderia a performance ser uma expressão universal da significação humana, semelhante à linguagem? (Phelan, 1998, p. 6).

Mais tarde, Phelan especulou que o interesse acadêmico nos Estudos da Performance nesse período foi impulsionado, pelo menos em parte, pelo assalto pósestruturalista sobre a linguagem e o desejo de achar na experiência corporal uma outra fonte de autenticidade, seja qual for a razão, o interesse nos Estudos da Performance rapidamente se espalhou. Ao programa da Universidade de Nova Iorque logo se seguiram outros no mundo inteiro. Em 1988, Richard Schechner, trabalhando novamente como editor da revista The Drama Review, em cujas páginas ele originalmente havia definido esse novo campo de estudo, acrescentou ao periódico o subtítulo: The Journal of Performance Studies.

No âmbito da antropologia, as questões de Turner foram transmitidas após sua morte (em 1983) por Colin Turnbull e outros, em direções que continuaram a se sobrepor, de forma marcante, no desenvolvimento da Teoria da Performance no teatro. Em um artigo de 1990, publicado na coletânea de Schechner By Means of Performance, Turnbull mencionava de modo específico como o seu próprio trabalho aparentava se desenvolver em direções paralelas ao trabalho mais tardio desenvolvido por Turner. Ao recobrar a rejeição de Turner ao dualismo cartesiano, Turnbull sugere que isso representou uma grande mudança na antropologia moderna, visto que se passa do modelo do observador de costumes culturais neutro e objetivo para de um nativo de uma cultura, observando nativos de outra cultura, criando uma complexa interação de influência e ajustamento (Turnbull, 1990, p. 50-81). A autoconsciência desse processo sobre o que concerne ao antropólogo, ou a reflexividade, se tornou uma baliza do que tem sido chamado de reviravolta pós-moderna na antropologia, em particular desde o aparecimento, em 1986, da influente

Marvin Carlson, O Entrelaçamento dos Estudos Modernos da Performance e as Correntes Atuais em Antropologia

R.bras.est.pres., Porto Alegre, v.1, n.1, p. 164-188, jan./jun., 2011.

Disponível em http://www.seer.ufrgs.br/presenca 
coleção de James Clifford e George Marcus, intitulada Writing Culture: the poetics and politics of ethnography.

Turnbull cita ainda, com a chancela das intuições de Turner, que os processos performativos não podem simplesmente serem estudados objetivamente, não porque uma genuína objetividade é difícil, senão impossível, mas por força de que tais fenômenos podem apenas serem compreendidos por meio de participação direta, de uma rendição do eu para se tornar outro. Apenas por meio da performance pode a performance ser compreendida. Dwight Conquergood, um professor de antropologia que se tornou o chefe de departamento do segundo programa de Estudos da Performance nos Estados Unidos, da Northwestern University, publicou em 1991 um artigo de muita utilidade, intitulado Rethinking Ethnography. Nesse trabalho, Conquergood observou como duas das características mais proeminentes dos trabalhos em curso eram, primeiro, um "retorno ao corpo", o qual privilegiava o corpo com um lugar de conhecimento, e, segundo, uma mudança relativa ao modo como o mundo era visto, ou seja, do mundo como texto para um mundo como performance (Conquergood, 1991, p. 179-194).

Embora haja muito em comum entre esses desenvolvimentos na antropologia e na teoria etnográfica e o desejo de Turner de se livrar do modelo narratológico objetivo, eles também serviram para colocar em evidência o quanto esse último modelo dominava na obra de Turner, mesmo em seus últimos anos. Em 1995, a antropóloga dinamarquesa Kirsten Hastrup observou em seu estudo A Passage to Anthropology que a então chamada "antropologia performativa" de Turner estava "[...] ainda muito baseada numa visão clássica e observacionista da antropologia. Isso explica porque o foco esteja mais nas expressões da experiência que na experiência propriamente dita" (Hastrup, 1995, p. 82-83).

Neste contexto, as diretrizes sugeridas por Turner para colaborações entre antropólogos e praticantes de teatro têm sido bastante reveladoras. "Em primeiro lugar", diz Turner,

[...] antropólogos podem apresentar para seus colegas do teatro uma série de textos etnográficos selecionados pelo

Marvin Carlson, O Entrelaçamento dos Estudos Modernos da Performance e as Correntes Atuais em Antropologia

R.bras.est.pres., Porto Alegre, v.1, n.1, p. 164-188, jan./jun., 2011.

Disponível em http://www.seer.ufrgs.br/presenca 
seu potencial de performance. $\mathrm{O}$ etnotexto processado poderia, então, ser transformado em um roteiro preliminar viável. Aqui, o know-how dos artistas de teatro - seu sentido de diálogo; sua compreensão de cenários e adereços; ouvir por um, uma frase reveladora - a qual seria assunto para uma modificação contínua durante o processo de ensaio, o que levaria, por sua vez, a uma verdadeira performance (Turner, 1982, p. 115).

O processo permanece, em suma, surpreendentemente próximo de um modelo teatral tradicional, com um texto de base fornecendo uma estrutura narrativa que rege ao mesmo tempo o roteiro operativo. Como Hastrup acertadamente observa, o drama social de Turner constitui uma forma protoestética que se desenvolve, sendo justamente isso o que o torna tão adequado na ordenação de operações teatrais tradicionais. Para confirmar essa analogia, Turner propõe até que experimentações de suas idealizadas colaborações antropológico-teatrais sejam aconselhadas por antropólogos, os quais atuariam como etnodramaturgos e gestores literoantropológicos, cuja função seria a de garantir a "[...] fidelidade do roteiro em relação aos fatos descritos e à análise antropológica das estruturas e processos de um grupo" (Turner, 1982, p. 120). A contínua centralidade da narrativa como a base para a pesquisa antropológica já estava clara na coletânea organizada em 1986 por Turner e Edward M. Bruner intitulada The Anthropology of Experience, a qual destacava um artigo de Bruner cujo título era Ethnography as Narrative (1986).

No entanto, ao final dos anos de 1980, apenas uma década depois da germinal oficina conduzida por Turner e Schechner, uma mudança deveras significativa pôde ser observada em relação ao conceito de antropologia performativa. Em uma pesquisa de 1989, acerca de questões correntes no campo, chamada Paths Toward a Clearing, Michael Jackson demandava um retorno ao empirismo radical de William James - o qual rejeita a fronteira entre observador e observado do empirismo tradicional -, a fim de capturar o sentido da imediata, da ativa, da ambígua plenitude da existência, estudando "a

Marvin Carlson, O Entrelaçamento dos Estudos Modernos da Performance e as Correntes Atuais em Antropologia

R.bras.est.pres., Porto Alegre, v.1, n.1, p. 164-188, jan./jun., 2011.

Disponível em http://www.seer.ufrgs.br/presenca 
experiência dos objetos e das ações nas quais o eu é partícipe". O foco na "experiência vivida" leva, de acordo com Jackson, a uma preocupação relativa não à identidade e ao fechamento, mas ao jogo e à interação. Ela "[...] acomoda o nosso cambiante sentido de nós mesmos como sujeitos e objetos, como agindo sobre o mundo e tendo o mundo agindo sobre si, vivendo ao mesmo tempo com e sem a certeza de pertencer e ser estranho" (Jackson, 1989, p. 2-3).

$\mathrm{O}$ texto a que geralmente se credita com maior clareza a articulação dessa mudança é de autoria de Johannes Fabian, intitulado Power and Performance, publicado em 1990, ainda que sua obra tenha sido em certa medida antecipada por pesquisas no campo do Folclore americano e da Etnomusicologia. Em seu estudo acerca da música popular e do teatro no Zaire, Fabian defendeu um conceito muito mais radical do que Turner, de antropologia performativa. Enquanto Turner dava atenção principal à forma dramática ou performativa de erupções sociais e culturais, essas ainda eram concebidas e descritas discursivamente. Fabian, de outro lado, insistia que em relação aos principais aspectos da cultura, "ninguém, nem mesmo o nativo, teria informação que pudesse ser chamada e expressa em declarações discursivas" (Fabian, 1990, p. 19). Muito do conhecimento cultural, ele argumentava, está armazenado mais em ações do que propriamente em palavras. Fabian se opôs de maneira verdadeiramente performativa em relação à etnografia informativa, baseando sua pesquisa na proposição de que o conhecimento cultural estaria envolvido mais com a prática do que com o discurso, podendo, portanto, ser apenas compreendido por meio de sua encenação e não pela narração. A performance, para Fabian, não apenas forneceu um método mais adequado do que a narrativa de como as pessoas percebem sua cultura, como também, por força dessa mesma razão, constituía para o etnógrafo a forma mais adequada de produzir conhecimento sobre dada cultura. Para ele, aquela modalidade de etnografia na qual o etnógrafo determina suas perguntas e anota as respostas deve ser substituída por uma etnografia na qual o "[...] etnógrafo

Marvin Carlson, O Entrelaçamento dos Estudos Modernos da Performance e as Correntes Atuais em Antropologia

R.bras.est.pres., Porto Alegre, v.1, n.1, p. 164-188, jan.jun., 2011.

Disponível em http://www.seer.ufrgs.br/presenca 
não chama pela melodia, mas joga com ela" (Fabian, 1990 , p. 19). Como uma ênfase na participação, o conhecimento corporal e a experiência vivida tornaram-se centrais para a abordagem performativa na antropologia contemporânea, ao passo que a ênfase de Turner nas metáforas do drama e do teatro tornaram-se menos centrais. Ainda assim, apesar dessa divergência, ao final dos anos de 1980 se testemunhou uma outra criativa colaboração entre um renomado teórico e praticante do teatro e uma renomada antropóloga, o que, de certa forma, lembrou os interesses convergentes de Turner e Schechner no começo dos estudos modernos da performance, mas que também refletia claramente as significantes modificações que se deram em ambos os campos em franca evolução. Essa nova convergência tomou lugar na Dinamarca, reunindo a antropóloga dinamarquesa Kirsten Hastrup e um dos mais influentes diretores de teatro experimental do final do século XX, Eugenio Barba.

O caminho que levou Barba à Dinamarca e a essa colaboração foi longo e tortuoso. Nascido na Itáia, Barba emigrou para a Noruega e, em seguida, após ter se interessado pelo teatro, rumou para a Polônia para estudar direção com Jerzy Grotowski, uma estrela em ascensão no teatro polonês. Barba permaneceu três anos com Grotowski, durante o período no qual foram criadas as mais famosas produções do diretor polonês, tais como Hamlet, Fausto e Akropolis. O profundo interesse de Grotowski no treinamento físico do ator e nas técnicas de atuação não europeias, em especial as asiáticas, deixou uma marca em Barba, que se tornou, em muitos aspectos, o sucessor de Grotowski. Barba viajou para a Índia, em 1963, para estudar uma forma de dança dramática chamada Kathakali, até então virtualmente desconhecida para os ocidentais; ele escreveu um ensaio muito importante sobre isso. Seu primeiro livro, In Search of a Lost Theatre, tratava sobre a obra de Grotowski; além do mais, Barba coletou e editou a primeira publicação de ensaios e entrevistas de Grotowski, Towards a Poor Theatre, o qual se tornou um texto central para o teatro experimental internacional durante os anos de 1970.

Marvin Carlson, O Entrelaçamento dos Estudos Modernos da Performance e as Correntes Atuais em Antropologia

R.bras.est.pres., Porto Alegre, v.1, n.1, p. 164-188, jan.jun., 2011.

Disponível em http://www.seer.ufrgs.br/presenca 
Durante os anos de 1970, Grotowski e Barba tornaram-se ambos cada vez mais interessados em questões do âmbito da antropologia, todavia, suas pesquisas evoluíram em direções muito distintas, ainda que partissem da mesma base. Grotowski movia-se cada vez mais da produção teatral, estudando práticas religiosas asiáticas e desenvolvendo um programa de cultura ativa, para a exploração de relações interpessoais e quebra de barreiras entre os artistas e o público. Se esse trabalho tendia a psicoterapia, após 1976, com o Teatro das Fontes, sua pesquisa se dirigia cada vez mais no sentido da antropologia. Grotowski viajou para o México, Nigéria, Índia, Haiti, tentando encontrar elementos comuns entre performances rituais das mais variadas partes do mundo. Ele insistia que não tinha um interesse folclórico pelo exótico, mas que estava à procura de um sentimento de conexão com o mundo natural e a experiência humana desse.

Ao mesmo tempo, Barba estava desenvolvendo um projeto similar, no entanto, sem nunca abandonar o teatro, como o fez Grotowski. Convidado para sediar sua companhia experimental na cidade dinamarquesa de Holstebro, Barba estabeleceu lá um laboratório de teatro em que oferecia regularmente produções teatrais e no qual desenvolveu pesquisas no que chamou de Antropologia Teatral. Em 1979, ele criou a ISTA, International School of Theatre Anthropology. Barba tem sido muito cuidadoso ao distinguir o que ele chama de Antropologia Teatral de seus aparentes elementos constituintes. Não se trata do estudo do fenômeno performativo em várias culturas, questão central dos Estudos da Performance de Schechner e de muitas outras pesquisas antropológicas modernas, sequer de algo que se relacione com o que se pode chamar de Antropologia da Performance. Trata-se, ao invés disso, daquilo que Barba designou como sendo "comportamento cênico préexpressivo", o que estaria na base de diferentes gêneros, papéis e tradições culturais pessoais ou coletivas. O que distingue primariamente a performance da vida cotidiana, Barba tem argumentado, não é tanto aquilo que está envolvido no que Schechner chamou de "comportamento

Marvin Carlson, O Entrelaçamento dos Estudos Modernos da Performance e as Correntes Atuais em Antropologia

R.bras.est.pres., Porto Alegre, v.1, n.1, p. 164-188, jan./jun., 2011.

Disponível em http://www.seer.ufrgs.br/presenca 
restaurado", mas antes algo que se baseia em certos fatores fisiológicos que conferem ao corpo uma particular energia e interesse que assinala que o corpo está "atuando". Esses fatores, em nível "pré-expressivo" de performance, estão baseados sobre operações fundamentais do corpo no espaço, tais como peso e equilíbrio, os quais produzem efeitos que se repetem nas mais diferentes culturas. A Antropologia Teatral está, assim, interessada no estudo transcultural dessas operações. Há certa similaridade entre a abordagem de Barba e a de Turner, visto que ambos estariam interessados na recorrência desse material em variados contextos culturais. Todavia, Turner, como tributário da tradição estruturalista, acha uma recorrência de padrões narrativos, a ubiquidade do drama social, ao passo que Barba, baseando-se nos estudos dos processos físicos de Grotowski, está interessado nas operações pré-narrativas do corpo em si mesmo. Aqui, a passagem para a "antropologia performativa", o "retorno ao corpo" alcança uma de suas mais extremas formulações. Com efeito, se a antropologia é pensada como o estudo das expressões humanas, a Antropologia Teatral de Barba, especificamente o pré-expressivo, pode também ser chamada de pré-antropológica (Barba, 1991, p. 10; p. 187-188; p. 203).

Embora Barba tenha sempre insistido que seu estudo da pré-expressividade estava baseado sobre uma cuidadosa análise da prática real da performance de uma variedade de culturas, outros autores o acusaram de ser, de fato, intuitivo, se não abertamente místico. Teóricos dos Estudos da Performance, como Schechner e outros antropólogos de ponta, como James Clifford e Edward Bruner, têm argumentado que o esforço para encontrar algum tipo de universal pré-cultural por trás de textos construídos culturalmente, quer sejam performances ou análises de performance, permanece, ainda, dentro do domínio da construção narrativa. Algumas dúvidas acerca da abordagem de Barba marcaram grande parte do debate em torno de uma conferência sobre $O$ papel feminino, organizado pela ISTA de Barba, em 1986. Philip Zarrilli, ao transmitir essa conferência ao The Drama Review,

Marvin Carlson, O Entrelaçamento dos Estudos Modernos da Performance e as Correntes Atuais em Antropologia

R.bras.est.pres., Porto Alegre, v.1, n.1, p. 164-188, jan.jun., 2011.

Disponível em http://www.seer.ufrgs.br/presenca 
sentiu que Barba havia ignorado uma das principais ocupações da antropologia contemporânea, a reflexividade, a qual Zarrilli definiu como "escutar a ideologia implícita em nossa maneira de falar". A ideia de pré-expressividade de Barba, Zarrilli sentiu, não era apenas intuitivamente baseada, mas era desprovida dessa avaliação reflexiva (Zarrilli, 1988).

De fato, as dúvidas expressas sobre o trabalho de Barba por tais teóricos da performance, como Schechner e Zarrilli, não foram compartilhadas por Kirsten Hastrup, uma professora de antropologia social da Universidade de Copenhagen, que também participava dessa mesma conferência e a qual tomou como uma grande fonte de inspiração. Ainda que Barba tenha distanciado seu trabalho das operações habituais do campo da antropologia, Hastrup encontrou paralelos estimulantes entre os interesses de Barba e os seus. Diferentemente de Schechner e Zarrilli, a antropóloga relatou estar

[...] fascinada pela busca implícita de universais nas mais variegadas tradições de performance da Ásia e da Europa. O conceito que particularmente a atraiu foi a noção de 'presença' do ator na cena, a qual não se reduzia a uma questão de ordem meramente física. Referia-se à maneira pela qual o ator havia administrado sua energia e surpreendido a si mesmo diante do público (Hastrup, 1995).

Hastrup viu o potencial dessa abordagem esclarecedora sobre o desenvolvimento de suas próprias questões acerca da presença do antropólogo no campo, um tópico que havia se tornado cada vez mais importante na antropologia durante a década anterior.

Hastrup teria aparentemente concordado com Clifford e Bruner de que os antropólogos devem aceitar a inevitável influência da estrutura narrativa não apenas no relato da experiência, mas na experiência propriamente dita, e, como eles, teria percebido que o reconhecimento dessa dinâmica era essencial para evitar qualquer orientação cultural particular, tomada como universal. No entanto, ela também acreditava que as diferenças culturais sob os corpos habitados por toda a humanidade forneciam um terreno comum, o qual lhes permitiu serem

Marvin Carlson, O Entrelaçamento dos Estudos Modernos da Performance e as Correntes Atuais em Antropologia

R.bras.est.pres., Porto Alegre, v.1, n.1, p. 164-188, jan./jun., 2011.

Disponível em http://www.seer.ufrgs.br/presenca 
imaginativamente acessíveis uns aos outros. Ela viu uma convergência entre a procura de Barba por princípios comuns de performance e os argumentos do filósofo Americano Mark Johnson, sobretudo em relação ao seu livro The Body in the Mind: the bodily basis of meaning, imagination and reason, de 1987. Como bem sugere o título, Johnson argumentava que a linguagem proposicional que nós usamos para descrever tanto a experiência quanto o entendimento só é possível por causa de uma rede subjacente de estruturas não proposicionais que emergem da experiência corporal. Uma boa parte dessa experiência corporal é compartilhada trans-culturalmente, permitindo o contato imaginativo nesse nível entre culturas. Por exemplo, afirma Johnson, o fato de andarmos eretos naturaliza, por assim dizer, modelos culturais baseados nas distinções entre o que está acima e o que está abaixo.

$\mathrm{O}$ retorno ao corpo, à experiência vivida e à interação no estudo antropológico entre sujeito e objeto fez da reflexividade uma questão de interesse central no empirismo radical, o qual marcou essa nova orientação no campo. Algum grau de consciência do problema de importar nossas próprias pressuposições culturais e a experiência cultural dentro do trabalho de campo tem sido, por certo, operativo desde os primórdios do estudo antropológico. Todavia, dois desenvolvimentos em trabalhos antropológicos modernos tem mudado de maneira distinta a atitude do campo em direção a esses problemas. Um deles é a crescente consciência da dificuldade de falar de culturas distintas. Nas palavras de Arturo Escobar, em artigo de 1991 para a revista American Ethnologist,

[...] sociedades não são totalidades orgânicas com estruturas e leis como nós pensamos que elas sejam, até recentemente, mas antes entidades fluidas que se estendem por todos os lados por meio de migrações, atravessamentos de fronteira e forças econômicas; culturas não são mais vistas como delimitadas, distintas e localizadas, mas desterritorializadas e sujeitas a múltiplas hibridizações (Escobar, 1991, p. 673).

Marvin Carlson, O Entrelaçamento dos Estudos Modernos da Performance e as Correntes Atuais em Antropologia

R.bras.est.pres., Porto Alegre, v.1, n.1, p. 164-188, jan./jun., 2011.

Disponível em http://www.seer.ufrgs.br/presenca 
Desde esse ponto de vista, o antropólogo contemporâneo tem a responsabilidade não apenas de estar atento ao caráter proteiforme e híbrido da sociedade que ele está estudando, como também do fato de que seu estudo contribui em alguma medida para o processo de hibridização em curso.

$\mathrm{O}$ segundo desenvolvimento tem sido um deslocamento para uma preocupação quase exclusiva do campo antes relativa a outras culturas exóticas para um interesse na aplicação da análise antropológica a aspectos da própria cultura, incluindo o estudo antropológico em si mesmo. Na verdade, antropologia e antropólogos têm proporcionado um tema particularmente interessante de estudo, visto que seu trabalho está centralmente ocupado com a mistura cultural e a negociação. Em um ensaio intitulado Cosmopolitans and Locals in World Culture, de 1990, Ulf Hannerz recomendava especialmente o estudo antropológico de indivíduos ou grupos que fazem do atravessamento de fronteiras culturais seu negócio, tais como representantes da indústria do turismo, correspondentes estrangeiros e missionários (Hannerz, 1990). Michael Herzfeld em seu recente estudo de campo cita essa passagem positivamente e acrescenta que, pela mesma razão, "[...] antropólogos também deveriam ser um objeto de escrutínio etnográfico: sua posição na sociedade em geral, talvez um pouco como os bufões medievais, é suficientemente ambivalente para servir como pedra de toque para o surgimento de ideias mais gerais" (Herzfeld, 2001, p. 3).

Curiosamente, uma figura exponencial nessa reviravolta mais reflexiva e pessoal na antropologia moderna também participou na oficina de verão de 1979, a qual representou um papel germinal no desenvolvimento do campo dos Estudos da Performance no âmbito acadêmico norte-americano, muito embora seu nome não tenha, nem naquele momento e nem depois, sido associado de forma significativa a esse campo. Trata-se de Barbara Myerhoff, chefe do departamento de antropologia da UCLA (University of Califórnia, Los Angeles), cujo trabalho durante os anos de 1970 e 1980 foi fundamental para moldar o estudo antropológico do

Marvin Carlson, O Entrelaçamento dos Estudos Modernos da Performance e as Correntes Atuais em Antropologia

R.bras.est.pres., Porto Alegre, v.1, n.1, p. 164-188, jan.jun., 2011.

Disponível em http://www.seer.ufrgs.br/presenca 
ritual e das histórias de vida. Peggy Phelan tem argutamente observado que uma das coisas que mais a fascinou na origem histórica dos Estudos da Performance de Schechner/Turner foi a ideia que dois homens trouxeram à luz, uma particularidade que essa origem partilha com o campo da psicanálise, com Freud/Breuer ou Freud/Fleiss. É interessante especular também se a contribuição de Myerhoff para o surgimento desse campo foi maior, se sua mais reflexiva e pessoal reviravolta poderia ter colocado os Estudos da Performance na sua origem em direção a um interesse maior na reflexividade e na experiência pessoal, como tem sido caracterizado boa parte dos mais recentes trabalhos tanto nos Estudos da Performance - como, por exemplo, as contribuições de Peggy Phelan -, quanto na antropologia - como, por exemplo, os trabalhos de Hastrup.

Seja como for, a colaboração entre Eugenio Barba e Kirsten Hastrup nitidamente refletiu essa diferente orientação em ambos os campos, como também o fez o trabalho colaborativo precedente entre Schechner e Turner. Em 1987, tendo lido alguns relatos de trabalho de campo de Hastrup e se sentindo deveras intrigado pelos mesmos, Barba convidou Hastrup a visitá-lo em seu teatro. Ela esperava que ambos discutiriam preocupações comuns, tais como a ideia de pré-expressividade e a relação do corpo com a prática cultural, porém, para sua surpresa, Barba tinha outro projeto em mente. Qual seja, perseguir teatralmente o que Herzfeld e outros teriam sugerido antropologicamente, para fazer de um antropólogo, e em particular uma proeminente antropóloga, o objeto de estudo, de fazê-la a informante nativa de seu trabalho de campo antropológico/teatral. Hastrup encontrava-se regularmente com os atores que exploraram detalhes de sua vida pessoal, profissional e psicológica, com os quais criaram o espetáculo Talabot, pela primeira vez apresentado em setembro de 1988. Hastrup achou a performance desestabilizadora, induzindo inclusive a uma espécie de pânico. Uma performance que ao evocar sua realidade pessoal de repente tornou familiar a poderosa diferença entre uma monografia etnográfica e aquilo que Schechner tem

Marvin Carlson, O Entrelaçamento dos Estudos Modernos da Performance e as Correntes Atuais em Antropologia

R.bras.est.pres., Porto Alegre, v.1, n.1, p. 164-188, jan.jun., 2011.

Disponível em http://www.seer.ufrgs.br/presenca 
descrito como comportamento restaurado. Uma vez mais evocando as palavras de Schechner, Hastrup sentiu que o palco que a encenava havia passado da forma não-eu para a não-não-eu, tal como o renomado teórico dos estudos da performance descreve a mútua possessão do atuador e do papel atuado. Na sua posição de informante, Hastrup adquiriu uma nova forma de ver não apenas o processo antropológico como também a construção da identidade.

Ao tomar fragmentos dispersos de uma vida e juntando-os de tal forma a constituir um mito coerente, Barba e seus atores aparentemente teriam removido o centro da construção de Hastrup, teriam proporcionado a consumação de uma síntese, tal como Turner havia observado acontece com a morte. Por algumas semanas, Hastrup sentia-se desprovida de sua existência. Incapaz de falar de volta como uma personagem em seu drama da vida, um papel agora assumido pela Kirsten de Talabot; Hastrup pensou que ela poderia responder a isso como uma antropóloga. Isso resultou no artigo Out of Anthropology: the anthropologist as an object of dramatic representation, publicado na revista Cultural Anthropology, em 1992.

A partir dessa experiência, Hastrup veio a ter uma nova compreensão da importância da antropologia e de sua relação com a formação da identidade. Ela citava Johnson no sentido de que todos os seres estão continuamente em busca de uma identidade, ao mesmo tempo em que tentam formar essa identidade de acordo com um ideal imaginativo do que pode então ser; sugeria, ademais, que a prática antropológica afeta ambos os processos, visto que "[...] proporciona de um lado um conhecimento contextual e, de outro, contribui para um sentido transcultural de deliberação moral compartilhada" (Hastrup, 1992, p. 327-345). Na medida em que um sujeito adquire uma perspectiva por si mesmo, especialmente ao compartilhar da experiência de um outro, ideias pré-concebidas do eu são confrontadas, as quais podem ser, como Hastrup bem aprendeu em Talabot, extremamente dolorosas, ainda que o sofrimento desse eu recessivo, para utilizarmos as palavras de Hastrup, possam dar um lugar para um eu extático, como

Marvin Carlson, O Entrelaçamento dos Estudos Modernos da Performance e as Correntes Atuais em Antropologia

R.bras.est.pres., Porto Alegre, v.1, n.1, p. 164-188, jan.jun., 2011.

Disponível em http://www.seer.ufrgs.br/presenca 
um indivíduo que ganha acesso a um outro mundo. Antropologia, sugere ela, pode ser "[...] instrumental nessa sua encenação de uma experiência de subjetividade" (Hastrup, 1992, p. 327-345).

O livro mais recente de Hastrup, Action, publicado em 2004, continua a considerar o eu recessivo e o eu extático em dinâmicas sociais, constrastando dessa vez o "doloroso" com o "lúdico", ambos os quais constituem "uma parte integral da experiência social e da reprodução cultural". Ao continuar interessada nas preocupações comuns do teatro e da antropologia, Hastrup olha agora de maneira específica para o teatro como um espaço central da reprodução cultural e da exposição do corpo humano como "ao mesmo tempo o lócus do agenciamento e o ponto zero da percepção"; ela chama seu livro de uma "tentativa de reintroduzir o teatro numa antropologia geral". Sua perspectiva não é a do público, como foi o caso de Duvignaud e o dos sociólogos pioneiros do teatro, mas a dos criadores de teatro, a da dinâmica da motivação individual e da construção do personagem, a criação e a performance de um eu dentro de um particular laboratório etnográfico propiciado pela criação teatral (Hastrup, 2004).

Em mais de uma ocasião esse trabalho foi transmitido por uma relação de trabalho muito próxima com pessoas do teatro, dessa vez com John Barton, exdiretor da Royal Shakespeare Company, com quem Hastrup se encontrou em 1996, em Copenhagen. Baseada em sua experiência com Barba, Hastrup trabalhou com Barton e seus colegas, especialmente com a atriz Jane Lapotaire e a professora de técnica vocal Cicely Berry, complementando esse trabalho com conversações com outros atores e diretores, incluindo Jerzy Grotowski, o qual Hastrup visitou em 1997, na Itália. Sem dúvida, a influência de artistas britânicos foi decisiva para Hastrup vir a se focar na atuação shakespereana; seu livro recebeu, com efeito, o subtítulo Anthropology in the company of Shakespeare. Dada a corrente de internacionalização da performance e das reinvindicações interculturais do estudo antropológico moderno, incluindo, é claro, o de Hastrup, esse foco canônico

Marvin Carlson, O Entrelaçamento dos Estudos Modernos da Performance e as Correntes Atuais em Antropologia

R.bras.est.pres., Porto Alegre, v.1, n.1, p. 164-188, jan.jun., 2011.

Disponível em http://www.seer.ufrgs.br/presenca 
talvez possa ser visto como um pouco retrógrado. Todavia, Hastrup simplesmente vê a produção shakespereana como um particularmente bem documentado e acessível exemplo de uma dinâmica que, de fato, diz de toda a prática de teatro, a qual compartilha com a antropologia moderna uma preocupação central com o desfazer da velha oposição entre arte e argumento, ilusão e realidade, emoção e razão, estudando, ao invés, como tudo isso se "[...] mistura e se combina no impulso que leva à ação" (Hastrup, 2004, p. 14-18). O estudo das operações de agenciamento dentro de um particular espaço social tem sido sempre central para a investigação antropológica. Hastrup afirma que o teatro, por força de sua explícita natureza como um lugar de agenciamento, constitui um objeto particularmente esclarecedor para tal investigação. Assim, um quarto de século depois que o trabalho antropológico de Victor Turner possibilitou a Richard Schechner uma forma de olhar para o teatro desde uma nova perspectiva, Kirsten Hastrup tem utilizado as operações do teatro a fim de ter novas ideias sobre as preocupações antropológicas.

Em seu ensaio Selective Inattention, de 1976, Schechner criou um diagrama para sugerir a relação entre o "drama social" de Turner e o "drama estético" do teatro, um diagrama que tem sido largamente reproduzido nos trabalhos dos Estudos da Performance que se seguiram a esse. O diagrama consiste na figura de um oito deitado, em que de um lado o drama social é representado por um laço e, por outro laço, o drama estético, no qual a energia flui continuamente ao redor dessas voltas. A pessoa de teatro usa as ações da vida social como uma matéria prima para a produção do drama estético, ao passo que o membro da sociedade usa as ações tiradas do teatro como modelos para subsequentes ações sociais, o que por sua vez reabastece o teatro. $\mathrm{O}$ processo, como a figura sugere, é infinito (Schechner, 1976, p. 12).

Embora Schechner e Turner tenham visto esse diagrama - o qual reproduziram em seu livro From Ritual to Theatre - em relação à convergência que eles estavam rastreando entre organizações de narrativa cultural, após

Marvin Carlson, O Entrelaçamento dos Estudos Modernos da Performance e as Correntes Atuais em Antropologia

R.bras.est.pres., Porto Alegre, v.1, n.1, p. 164-188, jan.jun., 2011.

Disponível em http://www.seer.ufrgs.br/presenca 
vinte e cinco anos tal esquematização permite ainda ser vista como representante das mútuas trocas em curso e como inspiração entre a antropologia e o teatro durante esse período. A inspiração crítica, teorética e artística tem igualmente fluido em torno dessa figura do oito, de Turner a Schechner e vice-versa, do trabalho combinado de ambos a Hastrup e Barba, que formaram um lugar mútuo de experimentação semelhante; e, então, numa outra volta, como Hastrup que tem estudado o trabalho de Barton e outros, a fim de aplicar as operações do drama estético de volta ao estudo da ação humana em geral. Turner pontuou, acerca do original diagrama de Schechner, que esse constituía uma importante tentativa de mostrar a relação entre o drama social e o teatro, mas isso talvez tenha sido sobremaneira "equilibrado" quando foi sugerido um movimento mais cíclico que propriamente linear (Turner, 1982, p. 74). A influência mútua em curso entre o teatro e a antropologia tem apoiado essa reserva, na medida em que essa interação continua, todavia é claro que ela evolui, atuando sobre e refletindo as perspectivas sempre cambiantes de ambos os campos.

\section{Notas}

${ }^{1}$ N.R.: no Brasil, o livro foi traduzido como A representação do eu na vida cotidiana (Editora Vozes, 2006). Todavia, consideramos que uma tradução mais adequada do título poderia ser A presentificação do eu na vida cotidiana.

\section{Referências}

BARBA, Eugenio. The Secret Art of the Performer. London: Routledge, 1991.

BRUNER, Edward M. Ethnography as Narrative. In: TURNER, Victor; BRUNER, Edward M. (Org.). The Anthropology of Experience. Illinois: University of Illinois, 1986. P. 139-158.

CONQUERGOOD, Dwight. Rethinking Ethnography. Communication Monographs, London, Taylor and Francis Group, n. 58, p. 179-194, 1991.

Marvin Carlson, O Entrelaçamento dos Estudos Modernos da Performance e as Correntes Atuais em Antropologia

R.bras.est.pres., Porto Alegre, v.1, n.1, p. 164-188, jan./jun., 2011.

Disponível em http://www.seer.ufrgs.br/presenca 
DUVIGNAUD, Jean. Sociologie du Théâtre. Paris: Presses Universitaires de France, 1963.

ESCOBAR, Arturo. Anthropology and the Development Encounter. American Ethnologist, Arlington, American Anthropological Association, v. 18, n. 4, p. 673, 1991.

EVREINOV, Nicolai. The Theatre in Life. New York: Benjamin Blom, 1970.

FABIAN, Johannes. Power and Performance. Madison: University of Wisconsin Press, 1990.

GOFFMAN, Evring. The Presentation of Self in Everyday Life. New York: Garden City, 1956.

GURVITCH, George. La Sociologie du Théâtre. Les Letters Nouvelle, Paris, Denöel, n. 34-36, p. 196-210, jan./jun. 1956

HANNERZ, Ulf. Cosmopolitans and Locals in World Culture. Theory, Culture and Society, London, Sage, n. 7, p. 239-254, 1990.

HASTRUP, Kirsten. A Passage to Anthropology. London: Routledge, 1995.

HASTRUP, Kirsten. Action: anthropology in the company of Shakespeare. Copenhagen: Museum Tusculanum Press, 2004.

HASTRUP, Kirsten. Out of Anthropology: the anthropologist as an object of dramatic representation. Cultural Anthropology, Arlington, American Anthropological Association, v. 7, n. 3, p. 327-345, ago. 1992.

HERZFELD, Michel. Anthropology: Theoretical Practice in Culture and Society. Maiden: Wiley-Blackwell, 2001.

JACKSON, Michel. Paths Toward a Clearing. Bloomington: Indiana University Press, 1989.

PHELAN, Peggy. The Ends of Performance. New York: New York University Press, 1998.

SCHECHNER, Richard. Approaches to Theory/Criticism. Tulane Drama Review, New York, v. 10, 1966.

SCHECHNER, Richard. Drama, Script, Theatre and Performance. The Drama Review, New York, n. 17, set. 1973.

SCHECHNER, Richard. Between Theatre and Anthropology. Philadelphia: University of Pennsylvania Press, 1985.

SCHECHNER, Richard. Selective Inattention. Performing Arts Journal, Baltimore, John Hopkins University Press, v. 1, n. 1, spring 1976.

TURNBULL, Colin. Liminality: a synthesis of subjective and objective experience. In: SCHECHNER, Richard; APPEL, Willa. Means of Performance. Cambridge: Cambridge University Press, 1990. P. 50-81.

TURNER, Victor. From Ritual to Theatre. New York: PAJ Publications, 1982.

Marvin Carlson, O Entrelaçamento dos Estudos Modernos da Performance e as Correntes Atuais em Antropologia

R.bras.est.pres., Porto Alegre, v.1, n.1, p. 164-188, jan./jun., 2011.

Disponível em http://www.seer.ufrgs.br/presenca 
ZARRILLI, Phillipp. For Whom is the 'Invisible' Not Visible? The Drama Review, New York, New York University, v. 32, n. 1, p. 95-106, spring 1988.

Marvin Carlson é professor emérito do Programa de Pós-Graduação em Teatro da CUNY (City University of New York). É autor de muitos livros sobre teatro e performance. Entre esses, vale destacar: Teorias do Teatro, publicado no Brasil pela UNESP e Performance: uma introdução crítica, lançado pela UFMG.

E-mail: mcarlson@gc.cuny.edu

Traduzido do original em inglês por Marcelo de Andrade Pereira e revisado por Gilberto Icle

Recebido em maio de 2011 Aprovado em junho de 2011

Marvin Carlson, O Entrelaçamento dos Estudos Modernos da Performance e as Correntes Atuais em Antropologia

R.bras.est.pres., Porto Alegre, v.1, n.1, p. 164-188, jan./jun., 2011.

Disponível em http://www.seer.ufrgs.br/presenca 